The Economic Journal, 114 (March), C87-C94. (C) Royal Economic Society 2004. Published by Blackwell Publishing, 9600 Garsington Road, Oxford OX4 2DQ, UK and 350 Main Street, Malden, MA 02148, USA.

\title{
TRAINING AND THE NEW MINIMUM WAGE*
}

\author{
Wiji Arulampalam, Alison L. Booth and Mark L. Bryan
}

\begin{abstract}
Using the British Household Panel Survey, we estimate the impact of the national minimum wage, introduced in April 1999, on the work-related training of low-wage workers. We use two 'treatment groups'- those workers who explicitly stated they were affected by the new minimum and those workers whose derived 1998 wages were below the minimum. Using difference-indifferences techniques for the period 1998 to 2000, we find no evidence that the introduction of the minimum wage reduced the training of affected workers and some evidence that it increased it.
\end{abstract}

Human capital theory predicts that the introduction of a minimum wage in competitive labour markets will reduce general training investment by covered workers who can no longer finance such training through lower wages (Rosen, 1972). However if the low-paid labour market is imperfectly competitive, firms will be more likely to pay for general training, although under-provision may result; see inter alia Stevens (1994); Acemoglu and Pischke (1999). Intuitively, the monopsonistic character of the labour market compresses workers' returns to human capital, allowing the firm to keep some of the surplus. By compressing wages further the introduction of a minimum wage can increase training.

Early empirical studies that looked at the effect of training on wage growth found minimum wages to lower wage growth (Leighton and Mincer, 1981; Hashimoto, 1982). However more recent studies - all using US microdata - perform more direct tests with better data but with mixed results. While Schiller (1994) and Neumark and Wascher (2001) found that workers subject to a minimum wage received less training, Grossberg and Sicilian (1999) and Acemoglu and Pischke (2003) found no clear evidence either way.

A UK National Minimum Wage (NMW) was introduced on $1^{\text {st }}$ April 1999. It followed a period of 6 years, from the abolition of the Wages Councils, during which there was no statutory wage-floor in any sector but agriculture. The Government views the NMW as an important cornerstone of Government strategy aimed at providing employees with decent minimum standards and fairness in the workplace' [http://www.dti.gov.uk/er/nmw/index.htm]. At the same time it emphasises the development of workforce skills - 'particularly the basic skills of some adults' [http://www.dfes.gov.uk/research/]. Our analysis empirically investigates if the two goals are compatible.

Our study provides the only investigation of the training effects of minimum wages in Britain. Moreover it utilises important new data from the British Household Panel Survey (BHPS) - on both training and whether or not individuals' wages were increased to comply with the NMW - facilitating a comparison of

* This research was supported by the Leverhulme Trust Award F/00213C 'Work-related Training and Wages of Union and Non-union Workers in Britain'. For helpful comments, we thank an anonymous referee, Mark Stewart and seminar participants at the University of Essex, the Australian National University, the Policy Studies Institute and the Centre for Economic Performance. 
training evolution across various groups. We use individuals' responses as to whether or not they were affected by the NMW to identify groups 'affected' and 'not affected'. We compare these results to those derived using an alternative definition based on hourly wages. Our methodology is similar to that of Stewart (2003), who uses the BHPS to analyse the employment effect for low-wage workers of the NMW.

\section{Empirical Framework}

We estimate the mean impact of the NMW on training for those affected by this policy intervention using the difference-in-differences estimator in the context of a Linear Probability Model (LPM).

Let $T_{i t}=1$ if individual $i$ received any training (to increase or improve skills in the current job during the past 12 months) in period $t$ and zero otherwise. Then

$$
\Delta T_{i t}=\Delta \mathbf{X}_{i t} \boldsymbol{\beta}+\alpha+\gamma A_{i}+\Delta \varepsilon_{i t}
$$

where $A_{i}=1$ if individual $i$ is in the affected group and zero otherwise; $\mathbf{X}_{i t}$ is a vector of individual and job characteristics influencing the outcome variable; and $\gamma$ is our parameter of interest. Differences in training experiences common across individuals due to, say, business cycle effects, are captured by $\alpha$. The equation implicitly allows for individual-specific unobservable effects that may be correlated with some of the regressors. $\Delta \varepsilon_{i t}$ is allowed to have arbitrary heteroscedastic covariance matrix in the LPM estimation. We stress that all our analysis is conditional on employment. ${ }^{1}$

\section{The Data}

Our data are from Waves 8 to 10 of the BHPS. The pre-NMW data are from Wave 8 and the post-NMW data are from Wave 10, conducted in 1998 and 2000 respectively. $^{2}$

The BHPS is a nationally representative panel survey of private households in Britain. From Wave 8, a new format was introduced for work-related training. The new questions cover up to three training events since September of the previous year, and provide information on where training occurred, how it was financed, its duration, and if it led to qualifications. Our sample of individuals was interviewed in Wave 8 between August 1998 and March 1999 about training received since $1^{\text {st }}$ September 1997. In Wave 10 they were interviewed between September 2000

\footnotetext{
${ }^{1}$ Stewart (2003), using the BHPS, finds no statistically significant evidence of employment effects of the NMW. It should anyway be emphasised that our estimated model accounts for selection biases arising from correlation with unobserved individual-specific characteristics.

${ }^{2}$ We use the data from 1998 onwards because major changes to the training questions were introduced in 1998. See Booth and Bryan (2002) for discussion about the differences in the questionnaires and training responses before and after this change. Bryan (2002) analysed training changes over 19957 , when no minimum wage was in place, finding no significant differential effect for workers who would have been covered by the minimum wage. The government introducing the NMW came to power in May 1997, so one might have expected to see any 'announcement effect' reflected in reported training in 1997.
}

(C) Royal Economic Society 2004 
and May 2001 about training experienced since $1^{\text {st }}$ September 1999. Reported training therefore falls unambiguously before and after the introduction of the NMW. We do not use training data from Wave 9 since we cannot determine if reported training occurred before or after the NMW was introduced.

The NMW was introduced at three levels: a main rate of $£ 3.60$ per hour, a youth rate of $£ 3.00$ for $18-21$ year olds, and a special development rate of $£ 3.20$ for workers over 21 years old undertaking specific types of approved training. The existence of the development rate potentially distorts the training decision since employers can pay a lower wage in return for providing training. Although we are unable to identify explicitly individuals covered by this provision, in principle we can identify them indirectly by using a reported hourly wage measure which was introduced to the BHPS in Wave 9 (for hourly paid employees only). We found no such cases.

Our analysis covers employees aged between 18 and 60 years in Wave 8, who are not in the army, farming or fisheries, and with valid training information. Individuals reporting over 100 working hours per week (hours are used to derive hourly wages) were dropped. Where there were many missing observations on control variables, we created dummy variables indicating their status, to maintain reasonable sample sizes. Individuals must satisfy the selection criteria in at least Waves 8 and 10. For one of the treatment-control groups discussed below, they must also be present in Wave 9 .

\subsection{The Outcome Variables and the Treatment/Control Groups}

We use two outcome variables: changes in training incidence $\Delta T_{i t}$ and training intensity $\Delta T_{i t}^{*}$. These are identical unless training incidence is positive in both periods; then $\Delta T_{i t}^{*}=1$ if intensity increases, $\Delta T_{i t}^{*}=-1$ if intensity decreases and $\Delta T_{i t}^{*}=0$ if intensity remains the same.

We define two alternative treatment and control groups, summarised in Table 1. Treatment group 1 contains individuals whose derived hourly wage was below the NMW for their age in wave 8 . These individuals' wages should have been raised to the NMW in April 1999 (assuming their derived wages are free of measurement error and would anyway not have increased in real terms between Waves 8 and 9). Control group 1 comprises individuals earning between the NMW and $15 \%$ more than the NMW in Wave 8. To investigate spill-over effects, we include the group of individuals ('high-wage') from the rest of the wage distribution above $115 \%$ minimum wage in 1998.

Individuals replying positively to the new question, 'Has your pay or hourly rate in your current job been increased to bring you up to the National Minimum Wage or has it remained the same?' were categorised as belonging to treatment group 2. Since this question was only asked of individuals who did not change jobs between $1^{\text {st }}$ April 1999 and the date of interview (from August 1998 to March 1999), this definition will exclude some workers who were subject to the NMW in a new job. ${ }^{3}$

\footnotetext{
3 The treatment group will therefore tend to over-represent job stayers. However, insofar as individuals remain in their jobs because of characteristics, which are constant over time, the differencing estimator will eliminate potential selection bias.
} 


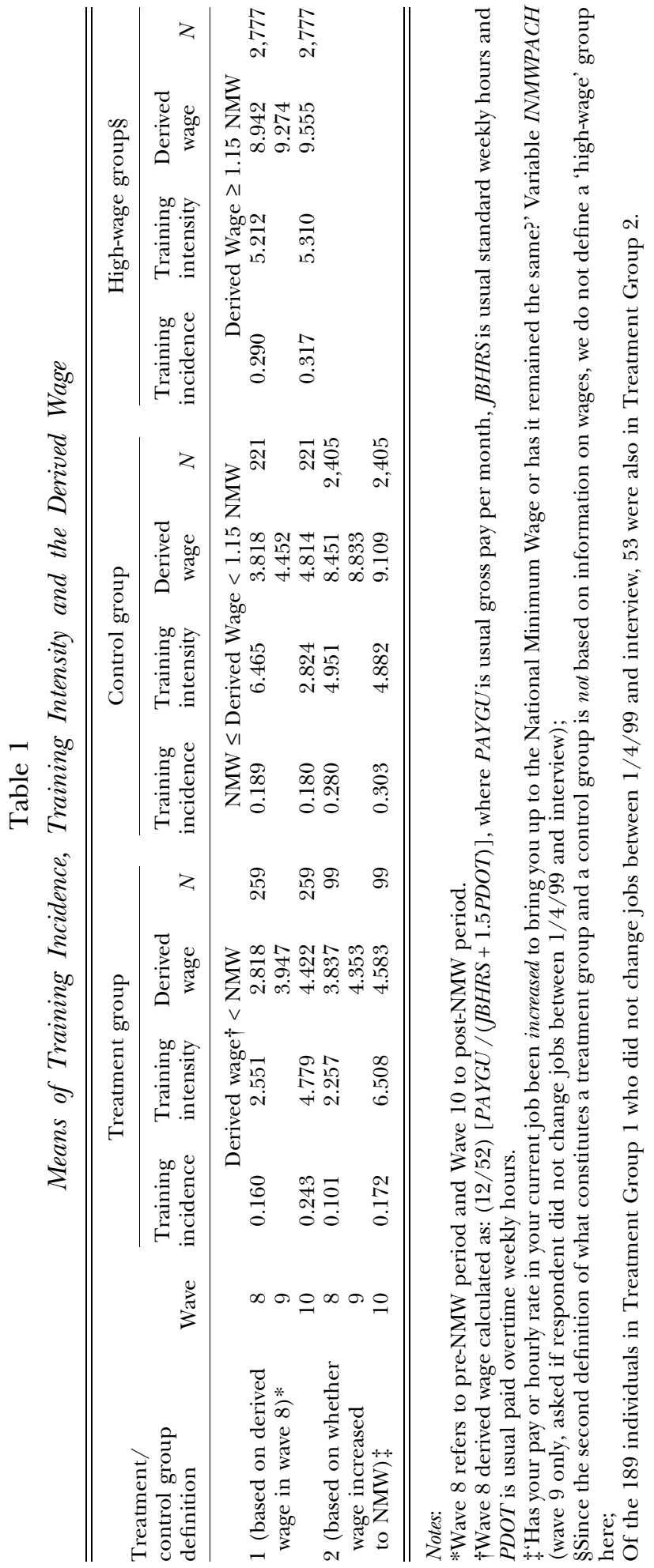

(C) Royal Economic Society 2004 
However, the question provides a treatment group that is arguably less prone to measurement error than the derived wage used for treatment group 1. Our control group 2 is corresponding individuals who were job-stayers and who answered no to the above question. Since the question was only asked in Wave 9, this selection requires individuals to be present in all three waves $(8,9$, and 10$)$. The sample size is therefore smaller than for treatment group 1. Since the definition is based entirely on a question that does not use the wage information, we do not include any other groups in this specification.

Table 1 reports mean training for the pre and post NMW periods. Training incidence typically increased in all groups, with a particularly marked proportionate increase in the treatment groups. For example, incidence in treatment group 2 increased from 0.10 in wave 8 to 0.17 in wave 10 ; in control group 2 , incidence went from 0.28 to 0.30 . Despite the increases, training is much less prevalent amongst workers earning close to the minimum wage than in the higher-paid groups.

The pattern is less clear when we consider (unconditional) training intensity. In treatment group 1, mean intensity rose from 2.6 days in wave 8 to 4.8 days in wave 10. In control group 1, intensity fell sharply from 6.5 days to 2.8 days. An increase over the period, from 2.3 days to 6.5 days is observed in treatment group 2. In the two groups of higher paid workers ('high-wage' group 1 and control group 2), intensity, like incidence, is quite stable at around 5 days a year. The volatility in the smaller groups is possibly caused by their sizes, or by the noisiness of training intensity. If so, incidence change $\Delta T$ may be the preferred dependent variable. In the next Section we present results for both $\Delta T$ and $\Delta T^{*}$ and highlight the differences in the model estimates.

\section{Results}

The raw difference-in-differences estimates of (1) with no additional controls are reported in Table 2, columns (1)-(4). Columns (1) and (2) show the results for $\Delta T$ (incidence-changes) and columns (3)-(4) the results for $\Delta T^{*}$ (intensity-changes). Column (1) indicates that the training probability in treatment group 1 increased by about 9 percentage points more than it did in the control group. This increase is statistically significant at the $5 \%$ level. The training probability also increased in the high wage group relative to the control group but the coefficient is not statistically significant. This suggests no spill-over effect of the NMW into this group. From column (2) where we use treatment and control groups 2, we see that, although training incidence increased more in the treatment group (by 5.0 percentage points) than in the control group, the estimate of the effect of the NMW on the training probability is not statistically significant at conventional levels. In this equation, however, the constant, capturing the trend increase in incidence, is significant at $10 \%$. The differences between columns (1) and (2) may be because control group 1 comprises workers just above the NMW, whereas control group 2 contains higher paid workers as well.

However, the results in columns (3) and (4) show that a similar result is obtained when information on changes in intensity is incorporated into the definition of training. More specifically, affected workers appear to be 10 percentage

(C) Royal Economic Society 2004 


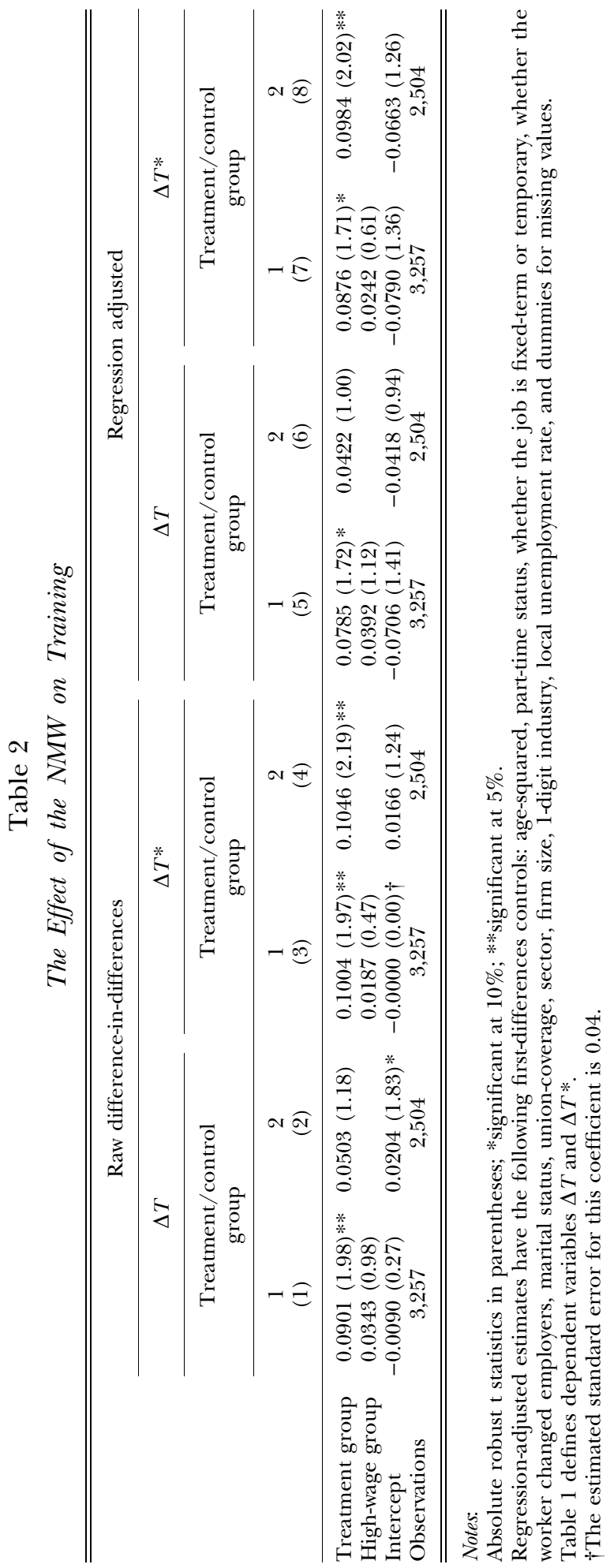


points more likely to experience an increase in training than workers in the control group. The increases are statistically significant. These results suggest that the NMW may have resulted in increased training. ${ }^{4}$

Columns (5)-(8) of Table 2 show the regression-adjusted difference-in-differences estimates of equation (1) incorporating individual and job characteristics. We exclude potentially endogenous variables like tenure and occupation. Insofar as the additional variables change significantly over time, they help control for individual differences in training growth. Regression-adjusted estimates of the treatment effect are slightly lower than the estimates in columns (1)-(4). Thus for treatment group 1, the NMW increases the training probability by 8.0 percentage points ceteris paribus, significant at the $10 \%$ level. The training probability in the high-wage group increases by 4.0 percentage points but this is not significant at conventional levels. Both figures are relative to the base of control group 1 . When the dependent variable is redefined to incorporate the information on intensity, the estimate, shown in column (7), is slightly higher at 8.8 percentage points.

In the specifications comparing treatment group 2 with control group 2 (columns (6) and (8)), the estimates are again similar to those without additional control variables (columns (2) and (4)). The NMW does not appear to significant affect the training incidence probability (the coefficient is positive), while it significantly increases intensity by 9.8 percentage points.

Overall, we interpret these results as providing support for the hypothesis that the NMW increased work-related training against the null hypothesis of no effect. ${ }^{5}$

\section{Conclusions}

We estimated the impact of the new national minimum wage on the work-related training of low-wage workers using two 'treatment groups'. These were first, those workers whose derived 1998 wages were below the minimum and, secondly, those workers explicitly stating they were affected by the new minimum. Using difference-in-differences techniques and information on training incidence and intensity, we found no evidence that the minimum wage introduction reduced the training of affected workers and some evidence that it increased it. In particular we found that the training probability increased by 8 to 11 percentage points for affected workers. Our findings provide little evidence supporting the human capital model as it applies to training and weak evidence of new theories based on imperfectly-competitive labour markets. Finally, our estimates suggest that two of the UK government's goals - improving wages of the low-paid and developing their skills - have been compatible, at least for the introductory rates of the minimum wage.

\footnotetext{
${ }^{4}$ We model the sign of changes in training intensity rather than the magnitude, since this relates directly to relevant theory. Modelling the exact change in training intensity would require us to address the issue that a change from 8 to 10 days is not necessarily the same as a change from 4 to 2 days or even a change from 2 to 0 days. Such analysis is beyond the scope of our current study.

5 In companion papers, we describe extensions of the analysis (Bryan, 2002; Arulampalam et al. 2003). These alternative models (that also investigate the sensitivity of our estimates to changes in the definitions of treatment group 1 and its control group) produced similar results to those reported here and our conclusions are unchanged.
} 


\section{University of Warwick}

Australian National University and University of Essex

University of Essex

\section{References}

Acemoglu, D. and Pischke, J.-S. (1999). 'The structure of wages and investment in general training', Journal of Political Economy, vol. 107 (3), (June), pp. 539-72.

Acemoglu, D. and Pischke, J.-S. (2003). 'Minimum wages and on-the-job training', Research in Labor Economics, vol. 22, pp. 159-202.

Arulampalam, W., Booth, A. L. and Bryan, M. L. (2003). 'Work-related training and the new national minimum wage in Britain', Working Papers of the Institute for Social and Economic Research, No. 2003-5, University of Essex.

Booth, A. L. and Bryan, M. L. (2002). 'Who pays for general training? Testing some predictions of human capital theory', mimeo, Australian National University, (June).

Bryan, M. L. (2002), 'The effect of the national minimum wage on training', ch. 3 of thesis in preparation for PhD Examination, University of Essex.

Grossberg, A. J. and Sicilian, P. (1999). 'Minimum wages, on-the-job training and wage growth', Southern Economic Journal, vol. 65 (1), pp. 539-56.

Hashimoto, M. (1982). 'Minimum wage effects on training on the job', American Economic Review, vol. 72, pp. 1070-87.

Leighton, L. and Mincer, J. (1981). 'The effects of minimum wages on human capital formation', in (S. Rottenberg, ed.) The Economics of Legal Minimum Wages, pp. 155-73, Washington DC: American Enterprise Institute.

Neumark, D. and Wascher, W. (2001). 'Minimum wages and training revisited', Journal of Labor Economics, vol. 19 (3), pp. 563-95.

Rosen, S. (1972). 'Learning and experience in the labor market', Journal of Human Resources, vol. 7, pp. 326-42.

Schiller, B. R. (1994). 'Moving up: the training and wage gains of minimum wage entrants', Social Science Quarterly, vol. 75 (3), (September), pp. 622-36.

Stevens, M. (1994), 'A theoretical model of on-the-job training with imperfect competition', Oxford Economic Papers, vol. 46, pp. 537-62.

Stewart, M. B. (2003). 'The impact of the introduction of the UK minimum wage on the employment probabilities of low wage workers', mimeo, University of Warwick, (February). 